\title{
Challenges of implementing internal control systems in Non- Governmental Organizations (NGO) in Kenya: A case of Faith- Based Organizations (FBO) in Coast Region
}

\author{
Hassan Sheba Abdulkadir \\ Masters of Business Administration student at Jomo Kenyatta University of Agriculture and Technology
}

\begin{abstract}
This paper seeks to expose the challenges of implementing internal control systems in NGO sector in Kenya with particular reference to FBOs in coast region of the country.

The study opens with a brief introduction of how NGOs operates and its reliance on informal management structure. It then demonstrates how internal control is crucial aspect of an organization's governance system and ability to manage risk. Challenges of implementing internal controls were looked at in three main perspectives; the limitations of financial controls, the scope of functionality of corporate governance controls and the practicability of ethics and compliance controls, in FBOs.

The evidence shows that FBOS in coast region mostly relies on traditional and informal control structure to fulfill their welfare agendas. Formal internal control systems as practiced in the corporate world have not fully been incorporated in the FBOs control systems. However, management controls that incorporate internal controls along with traditional welfare goals are considered a useful starting point in the move towards managing in a more competitive $N G O$ sector and FBOs are not an exception.

Keywords: financial controls, corporate governance, ethics and compliance controls
\end{abstract}

\section{Introduction}

Drawing from Statements of Standard Auditing Practices No. 6 (SAP 6) defines internal control as "the plan of organization and all the methods and procedures adopted by the management of an entity to assist in achieving management objectives of ensuring as far as practicable, the orderly and efficient conduct of its business, including adherence to management policies, the safeguarding of assets, prevention and detection of fraud and error, the accuracy and completeness of accounting records and the timely preparation of reliable financial information". Soudani (2013)

According to Mawanda (2008) internal controls are processes designed and affected by those charged with governance, management, and other personnel to provide reasonable assurance about the achievement of an entity's objectives. As such internal control plays a direct role in influencing management performance as they are charged to provide a reasonable assurance of the reliability of financial reporting, the compliance with laws and regulations and to uphold good corporate governance.

It is thus evidenced that the application of internal control systems has the potential to help in the effective and efficient delivery of services, but such an approach is relatively new and is sometimes at odds with the customary informal processes that have been applied in FBOs in coast region of the country.

However, while many FBOs have customarily relied on informal management processes to help develop and sustain their social capital, there has increasingly been pressure from donors, government and other official agencies for NGOs to show accountability, managerial competence and strong internal control system. Chenhall (2010) assert that NGOs are being confronted with the competitive nature of acquiring funds and need to demonstrate that they have particular competencies to funders, while at the same time continuing to adhere to their traditional welfare or development values.

This state of affairs creates a need to establish how the FBOs approach to service delivery affects the application of the increasingly important internal control systems.

\section{FBOs activities in the Coast region}

According to Ochanda (2012), FBOs have been extensively involved in the social and economic development in Sub-Saharan Africa through their work with the poorest and their presence in the most economically backward areas of the country.

In Kenya, FBOs are registered as Non-governmental Organization (NGO) or Community Based NGOs (CBO) and are so called faith-based because they are religiously motivated to operate their programs either as Christian, Muslim or Hindu oriented. Most of FBOs funding is through grants from donor agencies particularly their religious centres such as the Church and Islamic development agencies, and partly from contribution by its members and trustees (Ochanda: 2012). 
It is estimated that there are over $100 \mathrm{CBOs}$ and NGOs that can be categorized as FBOs in coast region. They range from small offices with two to three permanent staff and a number of local and foreign volunteers that run one program, to big organizations with over fifty staff operating various multimillion projects across the region. They also work with a diversity of actors including clerics, youth and village elders.

Among their areas of focus include; economic empowerment, education programs, health related programs such as HIV/AIDS awareness campaign, inter-religious understandings and human rights programs. Other activities of the groups include peace sermons, community security forums, inter-faith forums, football matches and poetry competitions in schools and religious centres.

While researches are available on their role and impact in socio-economic development in Kenya, minimal studies have been conducted to explore their internal administration and functionality of their management systems.

\section{General Objective}

The purpose of this paper is to find out the challenges of implementing internal control systems in Faith-Based Organizations in Coast region.

2.1 Limitations of financial controls

\section{Specific Objectives}

2.2 Scope of functionality of corporate governance controls

2.3 Practicability of ethics and compliance controls

\section{Challenges to effective implementation of control systems in FBOs}

An effective internal control system is one that exhibits certain characteristics that facilitate the evaluation and improvement of existing internal control systems by highlighting areas where the practical application of such guidelines often fails in many organizations. (IFAC: 2013)

Recently, policymakers have focused considerable attention on perceived weaknesses in the accountability and transparency of charitable organizations. This increased scrutiny is not necessarily unwarranted due to the recent financial scandals and the size of the NGOs sector to the economy (Petrovits: 2013). Opponents of any increased regulation argue that the current rules are adequate but need to be enforced, that most donors will not use any additional information to make a giving decision, and that organizations do not have the funds to comply with burden-some rules.

Moyer M.J. (2012) acknowledge that despite the contribution of faith-based development work, obstacles, and challenges still exist both from within the faith and from broader society. Traditionally, the management of NGOs has relied on informal processes based on shared norms and values of delivering humanitarian services, rather than on formalized procedures. The commitment of workers, volunteers and other organizational members has tended to be facilitated through strong reliance on a shared belief in the purpose of the organization, and not primarily through control system and remuneration based on profit making. However, the government is still considered the appropriate partner that can introduce regulatory framework that can help FBOs build capacity to manage themselves soundly (Salim: 2013)

Consequently, the adoption of more formal controls and businesslike management practices are often a source of conflict to the members of the organization and weakening of their strong self-driven commitment, which is key to the success of the NGOs goals and delivery of the much needed service to the community.

\subsection{Limitations of financial controls}

Bongani (2013) report that establishing internal control systems in organizations is critical to ensure the reliability of accounting records, because internal control systems can constrain management or staff s reported and possible random errors. This ensures the authenticity of the content of financial reporting to provide reasonable assurance to stakeholders and it becomes another important system arrangement to ensure reliable financial reporting.

Petrovits et. al. (2009) affirms that internal control systems are not new to the NGOs sector including the FBOs. Most organizations that receive external funding are subjected to rigorous internal control in line with the donor agency requirements. FBOs which exhibit internal control deficiencies may risk losing the much needed funding from the donors as they are accountable to them as well as the beneficiaries, the employees and other stakeholders.

However, due to the inherent limitations of internal controls and pressure, opportunity and excuses by management and perhaps the credibility of controls, discussing and benchmarking is still not high enough within FBOs in coast region. Though cases of fraud and other malpractices are rarely publicized by media and other communication channels, it is probable that misuse of funds due to lack of financial control systems is a reality in most FBOs. 
Experience reveals that the financial management processes of FBOs in coast region are generally weak and dominated by conditions of resource scarcity vis-à-vis the ever increasing agenda of social development activities on which such funds could be spent. Sustainable funding has helped many FBOs in coast region implement diverse programmatic interventions which has not only benefited the communities but has also improved the standard of living. However tough economic times buoyed by global recession have in one way or another affected global funding. Consequently many FBOs cease operations by the day due to lack of sustainable funding.

Unlike their counterparts in the profit-making, whose accounting system reflects the results of economic activities, expressing the efficiency with which the objective has been achieved; FBOs are mostly concerned with raising and expanding resources according to specific budget plans.

For many FBOs in coast region it is difficult to make the transition from values-based, informal management practices to an approach that emphasizes the financial implications of decisions. FBOs have traditionally been reluctant to import practices from the business sector. Chenhall (2010) added that an additional challenge concerns the potential impact of more formal management controls on the ability of organizations to develop social capital. Little is known about how formal controls affect the way NGOs develop and employ social capital, and how this influences their ability to deliver welfare services with increased pressure to be more financially efficient.

Another dilemma facing FBOs in coast region is that financial control system is often tied up with funds received from a particular donor. Therefore it is tailor-made to suit particular financial transactions and may not be applicable to other funds received by the FBO. With limited resources to have appropriate human resource, financial control systems therefore, become applicable on fund-to-fund basis or rather seasonal and not necessarily incorporated in the overall organization management system.

Petrovits et. al (2009) argues that Nonprofits organizations do not issue shares and their missions are not to maximize profit and therefore not accountable to shareholders. But they are accountable to donors who provide an important source of capital. It is a fact that FBOs in coast region do not have limitless resources and therefore, compete for contributions. Prior research suggests that FBOs managers, are rewarded for higher mission related spending and if such organizations have an internal control problem, donors could easily choose to contribute to another organization where the capital presumably will be more efficiently used.

\subsection{Scope of functionality of corporate governance controls}

Corporate governance is high on the agenda in all sectors - public, commercial and voluntary as it is the basic form of accountability in all bodies. Interestingly, corporate governance gained momentum due to management failure by most corporate bodies. Likewise FBOs working for the benefit of the needy, are increasingly expected to demonstrate how well are governed for purpose of accountability.

Machuki (2010) acknowledged that organizations operate in complex and dynamic business environments that require complex, but flexible, governance regulation reflecting the uniqueness of each situation arising from specific factors such as legal and financial systems, culture, corporate ownership structures and economic conditions. No single set of governance rules fits all organizations and situations and therefore governance should be understood in different contexts.

However, corporate governance as practiced in the corporate world is still a complex phenomenon in FBOs. Gateeba (2010) noted that a common problem is to do with the governance of the organizations and the relations between board members and staff. These stemmed largely from the boards' inability or unwillingness to carry out their responsibilities of governing the organizations. Board members often lacked the time or the expertise to be able to carry out these responsibilities effectively.

As a result, senior staffs were often left to make policy decisions with little or no support from board members. The governance picture of many FBOs is again quite complex. They are mostly governed by selfperpetuating, largely self-appointing committee members.

However, FBOs in coast region, since are mostly registered as CBOs, may also be subjected to some form of governance structure that is applicable to other organizations. In addition, since they also owe their allegiance to religious bodies such as the Church and Mosques, are also required to observe certain governance codes that are influenced by their respective religious practices.

There is no doubt that good corporate governance need to be applicable to all organizations to ensure that organizational goals and mission are realized through good stewardship of resources. But the debate is whether or not FBOs should adopt more rigorous corporate governance practices, particularly in relation to internal control. 


\subsection{Practicability of ethics and compliance controls}

FBOs that are registered as NGO's in Kenya are regulated by the National Council of NGOs, popularly known as the NGO Council. This is a self-regulating, non-partisan body comprising voluntary registered NGOs. It was established in August 1993 under the Non-governmental Organizations Co-ordination Act 1990 as a forum of all voluntary agencies. However NGOs are registered by NGO Coordination Board which oversees their operation on behalf of the government.

The NGO Council membership includes international, regional and national NGOs operating in Kenya and working with a host of CBOs and groups. It provides overall leadership to the NGO sector and champions the key values of probity, transparency, accountability, justice and good governance. It enhances the selfregulation of its members, and assists them to realize their potential in improving services that improve the socio-economic status of Kenyan society in pursuit of sustainable development. While a number of NGO's in Kenya have achieved administrative efficiency, most have major difficulties.

Efficiency cannot be guaranteed because of the nature of the NGO's themselves. Many of them are new, small and without guaranteed future. This is especially the case with local or national FBOs that are still struggling to put effective and efficient managements systems for good governance in place and whose survival largely depends on donor funding. There are also problems of legitimacy where FBOs may be easily set up. It all depends on whether one can write convincingly to donors. Such NGO's are weak and face the risk of lack of continuity.

\section{FBOs and Risk Management}

Risk is the probability of an event or action having an adverse effect on organization. Uncontrolled risk can severely handicap an organization and eventually result in its failure. It is important that risk management and control are not seen as a burden on business, rather the means by which business opportunities are maximized and potential losses associated with unwanted events reduced.

Consequences of risks within FBOs may include use of resources inefficiently or ineffectively resulting in shortages of funds or failure of a unit to meet goals, loss of assets due to theft or unintentional errors. Moreover, it may result in unreliable financial and operational reports resulting in poor decision making by management, while non-compliance with laws, rules, or regulations may result in financial penalties or damage to the reputation of the organization.

KPMG guidelines (1999) offer various techniques that can assist FBOs to identify and assess risks to their organizations. Though business oriented, current realities has made it necessary for FBOs to adapt to some of these techniques. Some are detail-based and offer quantification while others are scenario-based or qualitative.

\section{Literature Review}

Although the upsurge in interest in the non-profit sector in Kenya as a significant social and economic force can be described as recent, the sector has been around for centuries, with varying degrees of visibility, importance, and strength. The sector has deep historical roots. The broader social, economic and political experiences in the pre-colonial, colonial and postcolonial period have influenced overall development of the sector.

However Petrovits et. al (2009) argues that despite the extensive academic literature on internal controls in publicly traded companies, there is little research on internal control systems in the nonprofit sector.

Kenyan non-profit sector comprises thousands of non-state and non-commercial organizations, small and large, registered and unregistered, rural or urban-based, sometimes doing quite dissimilar things. Diversity remains one of the noticeable characteristics of the sector. The main types are NGOs, CBOs and self-help 'harambee' groups, cooperative societies and other associations. Other types include clubs of various shades, welfare organizations such as the home town associations, unions, trusts and foundations. There are also kinship and other traditional groups, and religious organizations such as those focused on welfare and service provisioning. (Kanyingi: 2007)

Gateeba (2010) observed that many donors view the NGOs as a better alternative to governmental agencies in getting services and assistance to those in need, especially in countries that are burdened by political favoritism and corruption. However, NGOs have also been involved in scandals that are as a result of having less than credible governance structure.

High-profile organizational failures typically lead to the imposition of additional rules and requirements, as well as to subsequent time-consuming and costly compliance efforts. With the right kind of internal controls, it will enable an organization to capitalize on opportunities while offsetting the threats and can actually save time and money and promotes the creation and preservation of value.

Chenhall et.al ((2010) argues that NGOs have become increasingly important in addressing humanitarian issues relating to welfare and developmental aid. Nevertheless, they face increasing pressure to 
demonstrate service delivery in cost efficient ways. This creates tension over delivering welfare services while operating within the constraints of cost management. The application of management control systems has the potential to help in the effective and efficient delivery of services, but such an approach is relatively new and is sometimes at odds with the customary informal controls that have been applied in NGOs.

According to Mawanda (2008) internal controls are processes designed and affected by those charged with governance, management, and other personnel to provide reasonable assurance about the achievement of an entity's objectives. As such internal control plays a direct role in influencing management performance as they are charged to provide a reasonable assurance of the reliability of financial reporting, the compliance with laws and regulations and to uphold good corporate governance.

However, the quality of the design of internal controls is very critical to the success of an organization. Yang (2009) confirms that to ensure the efficiency of internal controls, managers have to pay attention to the design of internal controls. It is important to ensure that internal controls are used to support NGOs in achieving their objectives by managing risks, while complying with rules, regulations, and organizational policies. NGOs should therefore make internal control part of risk management and integrate both in its overall governance system.

It is also imperative to note that the governing body and management need to foster an organizational culture that motivates members of the organization to act in line with risk management strategy and policies on internal control set by the governing body to achieve the organization's objectives. The tone and action at the top are critical in this respect.

The board should set appropriate policies on internal control and regularly assure itself that appropriate processes are functioning effectively to monitor the risks to which the organization is exposed and that the system of internal control is effective in reducing those risks to an acceptable level. It is essential that the right tone is set at the top of the organization - the Board should send out a clear message that control responsibilities must be taken seriously.

\section{Methodology}

This is a desk study that made use of the available research papers that have already been undertaken in this area.

\section{Conclusion}

This study examines the challenges of implementing internal control systems in FBOs in coast region of Kenya. Although FBOs have become established organizational actors within development policy and practice in coast region, critical questions are increasingly being asked of their performance and accountability. In general, the roles and activities of FBOs have been relatively well covered in the literature, but there is far less systematic research on internal controls and organizational processes and management.

The research focused on internal control systems related to the limitations of financial controls, the scope of functionality of corporate governance controls and the practicability of ethics and compliance controls It is evidenced that there are many positive changes in organizational performance that are associated with good internal controls within an organization. This will ultimately lead to sustainability of its programs as donors and other key stakeholders develop trust and support its programs.

\section{Recommendations}

From the study findings, it is clear that FBOs are still struggling to entrench business-like internal control systems within their management structure.

The findings highly suggested that FBOs establish or enhance strong internal controls within their system that will improve performance and increase confidence of its financiers and important stakeholders.

It is also recommended that further research is done in the same area to cover other specific areas of internal, controls.

\section{Reference}

[1] Arel B. et al (2005). Evaluating Internal Controls: The Moderating Effect of Auditor Experience on the Persuasiveness of Evidence from Management Self-Assessment. W.P. Carey School of Business Arizona State University, Arizona.

[2] Bongani N. (2013). Application of Internal Controls in NGOs: Evidence from Zimbabwe. Journal of Finance and Accounting, 2013, Vol. 1, No. 2, 39-47. Science and Education Publishing

[3] Chenhall R. et. Al (2010).The role of management control systems in NGOs. Chartered Institute of Management Accountants, Volume 6, London, United Kingdom.

[4] Holt T. (2006). The Effects of Internal Audit Report Disclosure on Perceived Financial Reporting Reliability. The University of Alabama, Culverhouse School of Accountancy, Alabama.

[5] International Federation of Accounts (2003).Evaluating and Improving Internal Control in Organizations. International Federation of Accounts,New York. 
[6] Kanyinga K. et al. (2007). The Non-Profit Sector in Kenya: Size, Scope and Financing. Institute for Development Studies, University of Nairobi.

[7] KPMG(1999). Internal Control: A Practical Guide. Service Point (UK) Limited, United Kingdom.

[8] Mawanda S. (2008). Effects of Internal Control System on Financial Performance in an Institution of Higher Learning in Uganda: A case of Uganda Martyrs. Uganda Martyrs University.

[9] Moyer J.M. (2012) Learning, Faith, and Sustainability in Kenya: Considering the Work of Faith-Based Organizations. Natural Resource Institute, University of Manitoba, Winnipeg, MB Canada.

[10] Ochanda R.M.(2012).Faith Organizations and Social Economic Welfare inKenya. Lumen Publishing House, Nairobi.

[11] Patrick Magezi Ga Kateeba (2010).The Relationship between Governance and Quality of Financial Reports in NGOs: The case of local NGOs supported by AIM programme in Bushenyi, Ntungamo and Rukungiri districts. Makerere University, Kampala.

[12] Petrivits et. al. (2009). The Causes and Consequences of Internal Control Problems in Nonprofit Organizations. New York University Stern School of Business, New York.

[13] Salim M.O. (2013) Strategy Development in Faith-Based Healthcare Institutions in the Coast region of Kenya. University of Nairobi

[14] Soudani S. (2013). The Impact of Implementation of E-Accounting System on Financial Performance with Effects of Internal Control Systems. Research Journal of Finance and Accounting ISSN 2222-1697 (Paper) Vol.4, No.11, 2013Islamic Azad University U.A.E. BranchDubai.

[15] Vincent N. Machuki (2010). Corporate Governance Structures and Performance of HIV/AIDS NGOs in Nairobi. School of Business, University of Nairobi.

[16] Yang M. (2012).The Effect of Internal Controls Adaptability on Operating Performance. Fu Jen Catholic University, Taiwan 